\title{
DOSSIER
}

\section{El Seminario de Historia Rural Andina, 1966-2016}

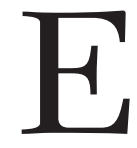

n cincuenta años de trayectoria y con cerca de 500 publicaciones el Seminario de Historia Rural Andina no contó con una publicación periódica. Su necesidad en la actualidad se debe no solo para establecer una comunicación más fluida con el mundo académico peruano e internacional sino también por las nuevas exigencias de la universidad pública peruana.

En tal sentido, esta revista creada como parte de las celebraciones por los cincuenta años del Seminario de Historia Rural Andina marca también su cambio institucional al de Instituto Seminario de Historia Rural Andina. Hasta junio de este año, el Seminario de Historia Rural Andina era una oficina dependiente del Rectorado que pese a su intensa actividad de investigación estaba alejada institucionalmente de la comunidad universitaria. Evidentemente, ello se debía a muchas razones. Resalto dos: una autonomía que la distanciaba del trabajo — y los problemas - de las facultades y al hecho de que la universidad le había dedicado más atención a la enseñanza que a la investigación. ¿Cómo podía integrarse una institución destinada exclusivamente a la investigación a facultades preocupadas sobre todo por la docencia? El alejamiento fue incluso físico: el local del Seminario de Historia Rural Andina se encuentra fuera de la Ciudad Universitaria, en el casi abandonado Colegio Real, ubicado en el centro histórico de Lima.

Con la entrada en vigencia del nuevo Estatuto de nuestra universidad esta situación ha cambiado. Como parte de una nueva política universitaria, que institucionalmente potencia la actividad de investigación, la experiencia del Seminario de Historia Rural Andina se ha integrado a la Facultad de Ciencias Sociales como Instituto Seminario de Historia Rural Andina. Este es un importante paso para el trabajo conjunto con profesores y estudiantes que esperemos de frutos en el corto plazo.

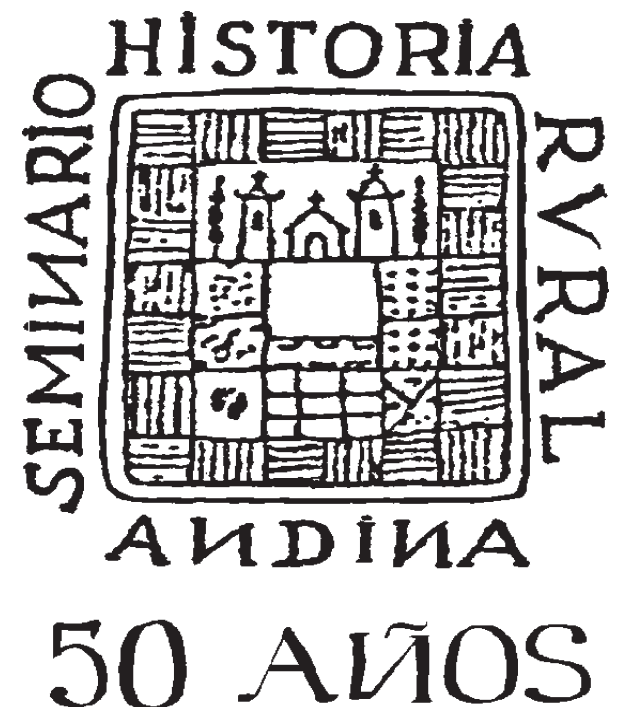

Ante estos nuevos tiempos, por la ya mencionado, es necesario reflexionar sobre el trabajo realizado. Es por ello, que este primer número está dedicado a realizar un primer balance de los cincuenta años de actividad del Seminario de Historia Rural Andina. En 1966 Pablo Macera tuvo la iniciativa de crear este espacio de investigación dedicado al mundo andino en una coyuntura de grandes cambios sociales y políticos, de movilización campesina, reforma agraria y el gobierno nacionalista de Juan Velasco Alvarado. Con el transcurso de los años el objetivo primigenio se mantuvo pero se amplió a otras áreas temáticas. El balance bibliográfico de Rosaura Andazabal con el que se abre este dossier, nos presenta un panorama general del trabajo y producción del Seminario de Historia Rural Andina entre los años 1966 y 2016. 
Como afirma Alejandro Salinas, con Macera y el Seminario de Historia Rural Andina se dio inicio al estudio histórico moderno de la economía y sociedad peruana. Las monografías y series estadísticas publicadas se basaban en un intenso trabajo de archivo gracias a la participación de un diverso grupo de estudiantes y egresados provenientes de las carreras de Historia, Etnología y Sociología de la Universidad Nacional Mayor de San Marcos. En ese sentido, ya desde las características de su grupo de investigación, el Seminario de Historia Rural Andina presentó un interés multidisciplinario para acercarse al mundo andino primero y décadas después al mundo amazónico.

Es así que, como muestra Amparo Alí Chávez en su artículo, en 1966 Macera llegó al sitio arqueológico de Pacopampa e impulsó el estudio del periodo formativo invitando a jóvenes arqueólogos de diferentes instituciones. Ello permitió tener después un área de investigación arqueológica en el Seminario de Historia Rural Andina a cargo primero de Daniel Morales y después de Jaime Miasta realizando un trabajo siempre vinculado con las otras áreas de trabajo (economía, arte, etc.). En la actualidad, las investigaciones en Pacopampa aún continúan gracias a un convenio firmado con el Museo Nacional de Etnología de Japón en el año 2005.

A partir de la década del 1970 el interés de Macera en el arte popular y la oralidad andina impulsó otra línea de investigación en el Seminario de Historia Rural Andina con trabajos hoy clásicos y cuyas perspectivas se ampliaron en la década de 1990 al mundo cultural amazónico, como Rosaura Andazabal y María Belén Soria, respectivamente, analizan en sus artículos. Es preciso señalar que este trabajo académico se vinculó con la promoción de las obras de los artistas andinos y nativos, dándoles protagonismo además en las publicaciones como fue el caso de Carmelón Berrocal y Víctor Churay, por mencionar solo dos nombres representativos.

Por lo mencionado hasta aquí, es evidente que Pablo Macera definió la línea de investigación del Seminario de Historia Rural Andina, aún incluso después de dejar la dirección en el año 2000. No obstante, los nuevos directores dieron énfasis a sus propia temáticas de investigación. En ese sentido, como desarrolla Omar Esquivel en el último artículo, Nanda Leonardini le dio fuerza a la historia del arte, publicando fuentes, tesis y rescatando del olvido a algunos críticos de arte (Luis Varela Orbegoso) y artistas (Óscar Pacheco, Félix Rebolledo).

Para finalizar esta presentación, este conjunto de artículos tienen como objetivo ofrecer al lector una visión general sobre la trayectoria del Seminario de Historia Rural Andina. Un material útil, además, para comprender el desarrollo académico de la disciplina histórica y las ciencias sociales en el Perú.

\author{
Alex Loayza Pérez \\ Responsable del número \\ Instituto Seminario de Historia Rural Andina
}

